Motrivivência Ano XXII, No 35, P. 316-329 Dez./2010

doi: 10.5007/2175-8042.2010v22n35p316

\title{
HISTÓRIA E HISTORIOGRAFIA DA EDUCAÇÃO DO CORPO E DO ENSINO DE EDUCAÇÃO FÍSICA EM INSTITUIÇÕES EDUCACIONAIS E LEGISLAÇÕES DE ENSINO DO PERÍODO REPUBLICANO
}

Gabriel Rodrigues Daumas Marques'

\section{RESUMO}

O presente trabalho realiza um levantamento bibliográfico por meio do Banco de Teses da CAPES (Coordenação de Aperfeiçoamento de Pessoal de Nível Superior) com o objetivo de analisar a produção e debates nas áreas da Educação e da Educação Física acerca da Educação do Corpo e do Ensino de Educação Física. Após localizar cento e quinze dissertações e teses produzidas entre os anos de 1994 e 2008, optamos por um recorte metodológico para analisar mais detidamente apenas as pesquisas que discorressem sobre legislações e/ou instituições educacionais de Ensino Primário e/ou Secundário no período republicano em nosso país. Tal recorte nos propiciou cinco teses e oito dissertações, cujos resumos analisamos e entrecruzamos discussões. As análises foram divididas em quatro momentos, a saber: instituições, legislações e regiões; recorte temporal; fontes e referenciais teórico-metodológicos; e objetivos, debates, resultados e conclusões. As discussões apresentadas são importantes e pertinentes para a área da Educação Física, destacando que a contribuição do campo de História da Educação pode ampliar os horizontes das investigações, no que tange ao trato com os documentos e o referencial teórico. Também consideramos fundamental a ampliação de investigações referentes ao cotidiano das práticas, disciplinas, experiências e culturas escolares, imersas em sua realidade social.

Palavras-chave: Educação do Corpo. Ensino de Educação Física. História da Educação Física. República.

1 Especialista em Educação Física Escolar (UFRJ). Mestrando em Educação (PPGE-UFRJ). Professor deEducação Física das redes municipais de Macaé e Rio de Janeiro. Contato: grdmarques@yahoo.com.br 
Ano XXII, $n^{\circ} 35$, dezembro/2010

\section{Introdução}

O presente estudo discorre sobre a história e a historiografia da Educação Física, temática extremamente importante para resgatarmos e mergulharmos mais profundamente em nossas origens. A identificação e o conhecimento das práticas pedagógicas dessa disciplina escolar no passado deve nos servir para aprimorar, renovar e criar práxis cada vez mais comprometidas com uma Educação crítica e reflexiva. O ensino da Gymnastica, Educação Physica e/ou outras nomenclaturas utilizadas para designar o que consideraremos Educação Física, caminhou fortemente pautado por preceitos mais gerais para a Educação do Corpo. Voltados majoritariamente para corpos infantis, preceitos higienistas, militaristas ou desportivistas compõem a nossa história disciplinar.

Nosso objetivo é analisar a produção e os debates do campo da Educação e da Educação Física, primordialmente, sobre a Educação do Corpo e o Ensino de Educação Física. Para materializar esse objetivo, o estudo recorreu metodologicamente ao levantamento bibliográfico realizado a partir da produção de teses e dissertações, encontradas entre 1994 e 2008, por meio do Banco de Teses da CAPES (Coordenação de Aperfeiçoamento de Pessoal de Nível Superior) ${ }^{2}$. Optamos por esse banco de dados por considerar que tais trabalhos acadêmicos se pautam por uma rigorosidade científica e consubstanciam maiores reflexões e contribuições para a área. Além disso, o instrumento por meio do qual coletamos vinte e cinco teses e noventa dissertações apresenta facilidade de acesso virtual e possui considerável organização ao nosso alcance e disponibilidade.

Após a leitura das fichas técnicas dos cento e quinze trabaIhos encontrados, recortamos cinco teses e oito dissertações para que possamos dialogar mais profundamente com os resumos, que apresentam questões mais específicas, escolhendo apenas aquelas que analisam legislações e/ou instituições educacionais de Ensino Primário e/ou Secundário no período republicano em nosso país. Diante do recorte, entrecruzamos aspectos referentes aos resumos dos treze

2 A busca foi realizada no dia 30 de agosto de 2009, através do seguinte endereço: http://servicos. capes.gov.br/capesdw/ $>$. A lista de títulos e respectivos autores das teses e dissertações encontra-se disponível no trabalho "História e Historiografia da Educação do Corpo e do Ensino de Educação Física". O Banco de Teses da CAPES é composto pelas teses e dissertações produzidas a partir de 1987. Porém, a primeira defesa encontrada pelas expressões por nós utilizadas se remete ao ano de 1994. Até a data de nossa busca, não foram encontradas defesas realizadas no ano de 2009. 
trabalhos, dividindo as discussões entre questões pertinentes como o referencial teórico, conceitos utilizados, questões teórico-metodológicas, trato com as fontes, recorte temporal etc.

\section{Instituições, legislações e regiões}

Os Estados do Paraná, do Sergipe, de Minas Gerais, do Rio de Janeiro e do Ceará são as regiões que figuram nos trabalhos após o recorte, demonstrando que temos muito a desvendar pela imensidão do país.

A Região Sul está representada em sua totalidade pela produção no Estado do Paraná. De maneira mais genérica, Puchta (2007) aborda historicamente a gymnastica no ensino público primário paranaense, preocupando-se com sua trajetória no plano das idéias e prescrições advindas de políticos e intelectuais da época. Aprofundando a partir de instituição educacional específica, Boschilia (2002) analisa o modelo educacional adotado por colégios masculinos católicos de origem francesa, pautando-se pelo estudo de caso do Colégio Santa Maria, fundado em Curitiba, em 1925. É mencionado o atendimento pelo colégio à significativa parcela da população escolar curitibana e explicitado que a fundação do colégio foi apreciada pela congregação
Marista da Província Central. Pykosz (2007) direciona sua investigação histórica para a disciplina escolar Higiene nos grupos escolares da capital paranaense. Sem anunciar uma região específica de análise, todavia defendida na cidade de Maringá, Gerelus (2007) apresenta uma análise histórica da obra de Rui Barbosa, objetivando compreender a Educação do Corpo das crianças brasileiras na proposta de reforma do ensino primário de 1883.

O pensamento educacional de Rui Barbosa também aparece na dissertação de Santana (2008), que busca investigar as práticas pedagógicas da educação do corpo no ensino primário sergipano. Nesse Estado nordestino, Nascimento (2001) procura descrever e analisar a implantação da disciplina Educação Física no Colégio Atheneu Sergipense, escolha justificada por conta do pressuposto de ser o primeiro colégio público organizado em Aracaju - nova capital da província de Sergipe - assim como a implantação do modelo do Colégio Pedro II em seu estatuto. Subindo um pouco mais no mapa brasileiro, a pesquisa de Rocha (2008) anuncia reconstituir a gênese da Educação Física Escolar nas escolas de Fortaleza.

A regiãoSudesteéa que mais aparece. Apesar de não explicitar no resumo qual(is) instituição(ões) é(são) analisadas e onde se situam, 
a tese de Parada (2003) - defendida no IFCS-UFRJ - identifica que, cotidiana e repetitivamente, os conceitos de ordem e disciplina são encontrados entre a espetacularização e a prática escolar. Amplamente, Ferraz (2001) possui o enfoque direcionado para a investigação das atividades físicas realizadas na escola secundária do Rio de Janeiro. Congregando importantes pesquisadores do campo, Minas Gerais é abordada pelos estudos de Vago (1999), ao problematizar o movimento de afirmação de uma nova cultura escolar após Reforma do Ensino Primário promovida pelo governo mineiro; Teixeira (2004), que objetiva analisar a inserção da ginástica como prática constitutiva da cultura escolar do Ginásio Mineiro, instituição fundada um ano após a proclamação da República e primeira escola de Ensino Secundário em Minas a se equiparar ao Ginásio Nacional, sendo, portanto, referência para as demais; Sousa (1994), que considera a história do ensino da Educação Física nos contextos mineiro e brasileiro por amplos mecanismos em quatro escolas públicas de $1^{\circ} \mathrm{e}$ $2^{\circ}$ graus, uma escola de educação de homens e três particulares - duas católicas e uma metodista; e Silva (1998), com pesquisa histórica de caráter exploratório sobre a presença da Educação Física na prática educativa de um dos principais estabelecimen- tos de ensino de Minas Gerais do período: o Colégio Granbery, escola considerada como um propício local para que uma cultura específica fosse cultivada, resultando práticas e representações educacionais que auxiliavam na construção de posturas discentes.

\section{Recortes temporais}

Apesar de já termos delimitado o período republicano no Brasil, tal recorte temporal abarca desde 1889 até os dias de hoje. Discorremos a seguir sobre os recortes feitos pelos autores, bem como os marcos ou justificativas de escolhas, quando apresentados(as).

Em termos de grande extensão, quase um século é abarcado por Sousa (1994), dentre os anos de 1897 e 1994, ano em que defende sua tese. Tal tese é a primeira defendida dentre os trabalhos que encontramos nas buscas. Trabalhando com períodos também extensos, Rocha (2008) analisa os anos de 1860 a 1930 e Ferraz (2001), os anos de 1851 a 1939, este justificando o estabelecimento de seu recorte temporal a partir dos marcos da primeira incursão de atividades físicas em escola secundária (1851) e a criação da Escola Nacional de Educação Física e Desportos (1939). Os trabalhos seguintes trazem recortes mais pormenorizados. 
Gerelus (2007) dedica atenção especial às alterações do modo de produção e suas relações com as necessidades prementes da sociedade brasileira em fins do século XIX e Silva (1998) investiga o início do século XX.

O período da Primeira República é o recorte de Vago (1999), Santana (2008), Puchta (2007) e Teixeira (2004). Essa última apresenta os marcos temporais da fundação da instituição educacional - 1890 - e o primeiro concurso para professor de Gymnastica e Educação Physica - 1916.

Enquanto Parada (2003) estuda a configuração da cultura cívica brasileira estruturada no Estado Novo, Boschilia (2002) inicia sua pesquisa com o ano de fundação do Colégio em 1925 até 1965 e Nascimento (2001) discorre acerca das aulas nas memórias de seus atores sociais que vivenciaram o período de 1916 a 1950. Com a justificativa do recorte mais explicitada, Pykosz (2007) historiciza seu objeto entre os anos de 1917 e 1932. Entre o "Programma do Grupo Escolar Modelo e similares", onde a disciplina é encontrada sob a denominação "Hygiene" - Decreto 420 de 19 de junho de 1917 - e a aprovação do Regimento Interno dos grupos escolares do Estado do Paraná - Decreto 1874 de 29 de julho de 1932 - é definido o recorte temporal, período durante o qual ocorrem importantes eventos que enfatizam a inserção dos preceitos higiênicos nas escolas: Congresso de Ensino Primário e Normal (1926), I Conferência Nacional de Educação (1927) e I a IV Congressos Brasileiros de Hygiene (1923-1929).

\section{Fontes e referenciais teórico- metodológicos}

Enquanto Parada (2003) explicita analisar as cerimônias $O$ Desfile da Juventude e A Hora da Independência, com intensa participação do público infanto-juvenil e associação à prática escolar de Educação Física e Canto Orfeônico, mas sem deixar transparente qual o manejo com suas fontes, não estão apresentadas as fontes nem o referencial teórico-metodológico em Ferraz (2001). Já Gerelus (2007) defende que o questionamento sobre a importância e os fins almejados nas propostas para a educação do corpo ocasionam a exigência de adoção de adequados procedimentos metodológicos assim como um trato detalhado com as fontes, para que seja possível evidenciar a singularidade do objeto, do posicionamento do autor, do contexto de produção da reforma, em meio às alterações sociais, políticas e econômicas que dialeticamente acompanharam a universalidade das discussões e 
necessidades. Apesar desse amplo panorama, não há clareza sobre quais fontes são por ele utilizadas. Sousa (1994) argumenta que a inter-relação de símbolos culturais, conceitos normativos, instituições e organizações sociais e da identidade subjetiva dos sujeitos masculinos e femininos são implicadas pela compreensão do gênero; entretanto, apenas cita que utiliza vários mecanismos - sem mencionar quais - e se baseia pela interferência de credos e classes sociais nas relações de gênero.

Santana (2008) elabora seu estudo a partir da utilização de variadas fontes, como relatórios de ensino, termos de visita, legislação e imagens, semelhante a Pykosz (2007), que reúne por meio de diferentes acervos relatórios de Instrução Pública e de Saúde Pública, programas de ensino, regulamentos de Instrução Pública, as teses dos eventos com conotações higienistas escolares da época e publicações da revista $O$ Ensino. A autora parte das noções de cultura escolar e história das disciplinas escolares para evidenciar as relações entre escolarização e higiene, tais como concepções, conteúdos, motivações dos propositores e destinação do tempo no currículo. Bastante rebuscado é o corpus documental de Puchta (2007), produzido por políticos, intelectuais, inspetores e professores escolares e composto por relatórios, regulamentos, regimentos e códigos de ensino referentes à instrução pública do período. O autor levanta questões relacionadas à história das disciplinas escolares e ao currículo, estabelecendo a necessidade do referencial teórico formado por Goodson (1995), Chervel (1990), Hebrard (1990) e Julia (2002).

Vago (1999) analisa centralmente as práticas escolares de Educação Physica e Gymnastica direcionadas para moldar os corpos das crianças, discorrendo acerca do processo de enraizamento dessa nova disciplina no ensino público primário de Belo Horizonte, de constituição de uma nova cultura escolar, a partir da reforma de 1906 e dos parâmetros da tríade educacional física, intelectual e moral. Ele recorre a documentos de distintas naturezas que atendiam às exigências da Secretaria de Estado dos Negócios do Interior, disponíveis no Arquivo Público Mineiro, possibilitando perceber vestígios direta e indiretamente das práticas das crianças nas escolas nos documentos tratados como fonte primária: relatórios anuais elaborados pelos secretários para envio ao Presidente do Estado, como relatórios quinzenais redigidos pelos inspetores escolares, relatórios anuais escritos pelas diretoras dos Grupos Escolares até o ano de 1918, ofícios, cartas, 
ordens de serviço etc. emitidos ou recebidos pelo Secretário do Interior, pelos funcionários da Secretaria, pelos inspetores, diretoras e professoras.

Em Silva (1998), as fontes utilizadas são os atos escritos dos poderes público e particular, periódicos e iconografias do Granbery, assim como entrevistas com ex-alunos. Boschilia (2002) utiliza fontes escritas e iconográficas, disponíveis no acervo do Colégio bem como a metodologia da história oral, problematizando conceitos como sociabilidade, identidade e memória. Nascimento (2001) também adota a história oral como possibilidade metodológica e utiliza fontes diversas, como jornais, portarias, relatórios e artigos. Faz referência a obras que possibilitam reconhecer a História da Educação Física em Sergipe e no Brasil, como Freire (1978), Haidar (1972), Nunes (1984), Sodré (1962), Marinho (1952), Melo (1996), Escragnolle (1997), d'Araújo (1870).

Por fim, Teixeira (2004) se orienta pelo referencial teóricometodológico da História Cultural para análise das fontes impressas e manuscritas, constituídas, dentre outras, por relatórios dos Reitores e dos Secretários do Interior ao Presidente do Estado, Legislação e Atas da Congregação. Rocha (2008) está amparada pela Teoria do Campo de
Bourdieu, referencial considerado pela autora ter possibilitado analisar a estrutura do campo, posição dos agentes e a construção do habitus como sistema de disposições socialmente constituídas, permitindo a institucionalização da Educação Física como referência ao estudo corporal na escola. A coleta de material empírico ocorre por meio da utilização de pesquisa documental extraída da literatura, fotografia, jornais, trabalhos acadêmicos e obras de memorialistas.

\section{Debates, objetivos, resultados e conclusões}

Discussões relacionadas ao higienismo e formação aparecem de maneira incisiva. São identificadas três vertentes principais no interior da escola para a formação do homem republicano: cuidados higiênicos (ex: vacinação, separação dos corpos doentes); exercícios corporais (ex: ginástica sueca, instrução militar, jogos, evoluções, marchas, escotismo); e desfiles cívicos e festividades escolares (ex: Independência de Sergipe, Proclamação da República) por Santana (2008). Além disso, é indicado que a criação da disciplina escolar Higiene e do serviço de Inspeção Médico-Escolar foram mecanismos importantes para a difusão das idéias médicas e ascensão do movimento sanitarista. 
Questões como a circulação das idéias médicas sobre a Educação no Brasil e seu lugar no Paraná; as preocupações relativas à construção de prédios, tempos e espaços escolares; e a configuração e principais características da Higiene enquanto disciplina específica permeiam os três capítulos do trabalho de Pykosz (2007). Nascimento (2001) se preocupa especificamente em reconhecer como ocorriam as aulas quando de sua implantação - no Colégio Atheneu Sergipense - e como se desenvolve o pensamento higienista na criação e desenvolvimento da Educação Física.

No diálogo estabelecido por Puchta (2007), perpassa o processo de escolarização da infância e da mocidade paranaense, procurando a aplicação das práticas corporais prescritas bem como os responsáveis por ministrá-las nas escolas. $\mathrm{O}$ autor indica que, diante da preocupação com a formação de cidadãos úteis e de espíritos esclarecidos por parte do interesse de políticos do Estado do Paraná, a gymnastica é inserida no ensino público primário paranaense, auxiliando na educação e constituição de corpos fortes e saudáveis. No caminho apreendido por Rocha (2008), são acompanhados os passos iniciais da então ginástica em algumas instituições educacionais de Fortaleza até chegar à denominação de Educação Física. Interessante destacar que o trabalho perpassa o embate dos agentes no movimento de banalizar a prática da disciplina na escola, ora pelos acrobatas (ginastas "marginais") ora pelos instrutores (militares ou normalistas). Com outro enfoque, Sousa (1994) entende que a Educação Física auxilia na caracterização sexual dos gestos e outras normas ao determinar turmas separadas por sexo; conteúdos diferenciados para homens e mulheres; e professor para alunos e professora para alunas. Teixeira (2004) entende que o acompanhamento dos vinte e seis anos da instituição - Ginásio Mineiro - e a presença da Ginástica - período em que ocorrem sua emergência, autorização, defesa, suspensão, reinserção e legitimação por força de lei e afirmação social como campo disciplinar - significou investigar o enraizamento da mesma como prática constitutiva da cultura escolar. A autora indica os seguintes elementos: a representação da ginástica como promotora de um corpo saudável, robusto e disciplinado; instrução de exercícios militares para o ofício da Guerra, com a formação de exército de jovens lutadores, produtivos e patrióticos; a exemplo do que ocorria na Europa, a esgrima enquanto prática específica do ensino secundário era componente da educação 
polida e concorria para a formação de verdadeiros cavalheiros. Pelos vestígios sobre a prática de Ginástica, foi possível aproximar-se aos métodos em circulação na Europa, diferenciando essa apropriação em virtude da realidade da instituição, das convicções e interesses daqueles que puseram-na em prática.

Situado dentre os estudos sobre os processos de construção das categorias de civilização e ordem nas modernas sociedades de massa, Parada (2003) identifica e encontra no cotidiano os conceitos de ordem e disciplina entre a espetacularização e a prática escolar. Já Gerelus (2007) apresenta a ocorrência de quatro momentos: as novas relações dos homens com seus corpos enquanto exigências do movimento do capital e de instabilidade nacional; a discussão das proposições da reforma - do Ensino Primário de 1883 - aliadas à necessidade de formação do trabalhador livre nacional; a análise da educação do corpo configurada no ensino primário; e as considerações sobre liberdade, enquanto valor de classe, que emoldura a defesa da educação integral para o referido intelectual. Silva (1998) intenta discutir, num contexto de primeiras solicitações do capitalismo em avanço, o uso do esporte como significativo meio para a instituição no período, atrelando à formação do homem pretendido pela sociedade urbano-industrial em desenvolvimento. A escola é considerada como um propício local para que uma cultura específica fosse cultivada, resultando práticas e representações educacionais que auxiliavam na construção de posturas discentes. A perspectiva do controle do corpo como forma de poder; o uso da competição como princípio norteador do trabalho esportivo e objetivando o rendimento; a convergência de discursos orais e escritos relacionados à questão higiênica; e a prática esportiva oferecida às alunas foram aglutinadas dentre as categorias analisadas. $\mathrm{O}$ trabalho evidencia alguns indicativos: um movimento de gênese do esporte escolar anterior ao que aponta a historiografia da área; a utilização do esporte como um símbolo do progresso pretendido e grande contribuinte da formação de uma elite intelectual para assumir cargos de responsabilidade e dirigir o país, ao formar o ideal de homem e assimilar a disciplina corporal que refletia os princípios da moral burguesa; e, referente à questão de gênero, a contribuição para a emancipação da mulher no esporte, visto que na década de 1920 já oportunizava a prática do esporte competitivo feminino.

Possuindo como objetivo analisar em que medida houve a capacidade das estratégias institucionais utilizadas para inculcar nos alunos uma identidade específica, 
mais visivelmente a noção de pertencimento a uma "comunidade de inscrição", Boschilia (2002) percebeu que, tal como os demais estabelecimentos católicos, os colégios Maristas eram estruturados visando uma contraposição ao ensino laico e aos modelos pedagógicos modernizados. Para que fosse criada uma identidade específica, com vistas à formação de um grupo de elite modelado por um sistema único de pensamento, sua especificidade passa pela adoção de um modelo que privilegiava a sociabilidade, juntamente com a educação do corpo, da alma e do intelecto. À elite estudantil, criada por meio de dispositivos modeladores de conduta, estaria atribuída a manutenção e reprodução dos valores morais e religiosos aprendidos no espaço escolar em diferentes setores da sociedade, tentando garantir a preservação dos espaços de poder da Igreja. Para alcançar tais objetivos, o modelo educacional efetivado pela congregação Marista oportunizava a convivência com as inovações do mundo moderno, apesar da rígida disciplina religiosa e pedagógica. Em Ferraz (2001), num plano específico, como objetivo, o estudo busca, ao revelar a dinâmica do processo de institucionalização do campo de conhecimento da educação física, demonstrar a complexidade de agentes, idéias e instituições envolvidas na disputa ideológica pela representação legítima de suas práticas sociais; mas também abordar o papel da educação na vida cotidiana dos cariocas, ao apreender e produzir comportamentos, hábitos, costumes, crenças, idéias etc. No plano geral, o objetivo apresentado é contribuir para o debate então atual da identidade epistemológica da educação física. O estudo é dividido em três partes, a saber, apresentação da base sóciocultural a partir da qual as atividades físicas aconteciam, destacando a análise das práticas desenvolvidas no espaço escolar; atenção central para as disputas de representações teóricas com pretensão de explicar e justificar as atividades físicas; e a apresentação dos desdobramentos práticos nos quais agentes e instituições se reuniram para garantir a constituição do campo acadêmicocientífico da educação física. A conclusão aponta para a observação de diálogo e negociação com a realidade sócio-cultural, imersa numa complexa arquitetura de agentes, idéias e instituições, apesar de haver um grupo de agentes em posição privilegiada de poder, que pretendia implementar seus projetos de educação física.

Para finalizarmos, Vago (1999) acompanha mais detidamente o enraizamento escolar da Gymnastica, a partir dos ordenamentos 
legais prescritos no período e dos relatórios produzidos pelos agentes escolares. Nesse processo de revelar a cultura escolar enquanto cultivo de corpos, o autor conclui que a Ginástica foi um dos dispositivos mobilizados para o movimento de afirmação de uma nova cultura escolar. A partir da orientação do primado que regula a Ginástica, apresenta o propício cenário para a afirmação e legitimação da pedagogia moderna e científica centrada na tríade educação moral, intellectual e physica..Na visão do autor, os impasses e precariedades desse processo não impediram de ver, no entanto, o investimento de uma época sobre o corpo das crianças, no âmbito da escola.

\section{Considerações finais}

A leitura e a conseqüente análise dos resumos são importantes para ampliar o cabedal de conhecimentos relativos ao cenário da academia em nossa área. O leque de autores, de metodologias, de objetos, de problemas etc. nos coloca desafios mas também limites, instigando-nos à pesquisa e chamando a atenção para que possamos produzir conhecimentos úteis ao conjunto da sociedade.

Em minha trajetória como estudante, professor, pesquisador e militante, percebo o tema que se segue pouco abordado, explorado e desenvolvido: a história do ensino da educação física, que implica no estabelecimento de diálogos com a infância, a educação do corpo, as instituições educacionais e a cultura escolar. A aproximação e o mergulho no campo da História da Educação possibilita ampliar os horizontes da pesquisa. Certamente o conjunto de questões apresentado; o manejo dos documentos enquanto um duplo movimento de fonte de informação historiográfica e objeto de investigação; e também o referencial teórico utilizado se constituem em importantes ferramentas para impulsionar novas pesquisas.

Ao entrelaçarmos objetos, teorias e metodologias das dissertações e teses recortadas, julgamos ser perceptível um avanço nas discussões do tema. Na maioria dos casos, sem desconsiderar a realidade sócio-cultural, é direcionado um olhar para determinadas instituições educacionais imersas num certo período temporal. Aqui acreditamos que novos manejos e olhares com as fontes propiciem essa realidade, investigando o cotidiano das práticas, disciplinas, experiências e culturas escolares sem abandonar as questões de produção e reprodução material da vida em uma sociedade dividida em classes sociais. Afinal, como pesquisadores e como seres humanos, não somos neutros e 
devemos saber com quem caminhamos e que lado defendemos, valendo com coerência tanto para nossas investigações quanto para nossas práticas pedagógicas.

\section{Referências}

Banco de Teses da CAPES. Disponível em < http://capesdw.capes.gov. br/capesdw/ > Acesso em 30 ago. 2009.

BOSCHILIA, Roseli. Modelando condutas: a educação católica em colégios masculinos (Curitiba:1925-1965). Curitiba, 2002. 226 p. Tese (Doutorado em História) - Setor de Ciências Humanas, Letras e Artes, Universidade Federal do Paraná, 2002.

FERRAZ, Marcus Vinicius Marques. A institucionalização do campo de conhecimento da Educação Física: uma história do ensino da Educação Física nas escolas secundárias do Rio de Janeiro (1851-1939). Rio de Janeiro, 2001. 156 p. Dissertação (Mestrado em Educação) - Faculdade de Educação, Universidade do Estado do Rio de Janeiro, 2001. GERELUS, Sérgio Henrique. Rui Barbosa e a educação do corpo na Reforma do Ensino Primário. Maringá, 2007. 129 p. Dissertação (Mestrado em Educação) - Universidade Estadual de Maringá, 2007.

NASCIMENTO, Randeantony da Conceição do. O atheneu sergipense e a educação física: (1916-1950) memórias. Rio de Janeiro, 2001. 131 p. Dissertação (Mestrado em Educação Física) Universidade Gama Filho, 2001.

PARADA, Mauricio Barreto Alvarez. Educando corpos e criando a Nação: cerimônias cívicas e práticas disciplinares no Estado Novo. Rio de Janeiro, 2003. 257 p. Tese (Doutorado em História Social) - Instituto de Filosofia e Ciências Sociais, Universidade Federal do Rio de Janeiro, 2003.

PUCHTA, Diogo Rodrigues. A formação do homem forte: Educação Física e Gymnástica no ensino público primário paranaense (1882-1924). Curitiba, 2007.126 p. Dissertação (Mestrado em Educação) - Setor de Educação, Universidade Federal do Paraná, 2007.

PYKOSZ, Lausane Corrêa. A higiene nos grupos escolares curitibanos: fragmentos da história de uma disciplina escolar (1917-1932). Curitiba, 2007. 161 p. Dissertação (Mestrado em Educação) - Setor de Educação, Universidade Federal do Paraná, 2007. 
ROCHA, Ariza Maria. De Ginástica à Educação Física nas escolas de Fortaleza (1860-1930): emergência e consolidação de um campo de saber. Fortaleza, 2008. 170 p. Tese (Doutorado em Educação) - Faculdade de Educação, Universidade Federal do Ceará, 2008.

SANTANA, Angélica Jesus de. As práticas pedagógico-educativas da educação do corpo no ensino primário em Sergipe - 1889-1930. Aracaju, 2008. 182 p. Dissertação (Mestrado em Educação) - Faculdade de Educação, Universidade Federal de Sergipe, 2008.

SILVA, Maria Cecília de Paula. O esporte na proposta pedagógica da educação física no colégio Granbery: uma compreensão histórica. Rio de Janeiro, 1998. 146 p. Dissertação (Mestrado em Educação Física) - Universidade Gama Filho, 1998.

SOUSA, Eustáquia Salvadora de. "Meninos, à marcha! Meninas, à sombra!" A história do ensino da Educação Física em Belo Horizonte (1897-1994). Campinas, 1994. 265 p. Tese (Doutorado em Educação) - Faculdade de Educação, Universidade Estadual de Campinas, 1994.
TEIXEIRA, Aleluia Heringer Lisboa. A Gymnastica no Ginásio Mineiro - Internato e Externato (18901916). Belo Horizonte, 2004. 175 p. Dissertação (Mestrado em Educação) - Faculdade de Educação, Universidade Federal de Minas Gerais, 2004.

VAGO, Tarcísio Mauro. Cultura Escolar, Cultivo de Corpos: Educação Physica e Gymnastica como práticas constitutivas dos corpos de crianças do ensino público primário de Belo Horizonte (1906-1920). Bragança Paulista: EDUSF, 2002. 
Ano XXII, n³5, dezembro/2010

\begin{abstract}
This piece of work presents a bibliographic survey using the Bank of Theses of CAPES (Coordination for the Improvement of Personnel with University Degree) with the aim of analyzing the production and arguments in the areas of Education and Physical Education concerning Body Education and Physical Education Teaching. After we have localized one hundred and fifteen dissertations and theses produced since 1994 until 2008, we made a methodological choice of analyzing only the researches about legislation and/or educational institutions of Elementary and/or Secondary Education during the Republican period in our country. This choice led us to five theses and eight dissertations which abstracts and arguments we analyzed. We have divided the results in four moments: institutions, legislation and regions; time reference; theoretical and methodological references; and aims, discussions, results and conclusions. The topics we mention are important and considerable for Physical Education area, emphasizing that the contribution brought by the History of Education may amplify the investigation horizons because of the detailed observation of the documents and theoretical reference. We also consider essential expanding the investigations about daily school practices, subjects, experiences and cultures immersed in their social reality.
\end{abstract}

Keywords: Body Education. Physical Education Teaching. History of Physical Education. Republic.

Recebido: março/2011.

Aprovado: abril/2011. 